\title{
Recent advances in metathesis-derived polymers containing transition metals in the side chain
}

\author{
Ileana Dragutan ${ }^{* 1}$, Valerian Dragutan ${ }^{* 1}$, Bogdan C. Simionescu ${ }^{*}$, Albert Demonceau ${ }^{3}$ \\ and Helmut Fischer 4
}

\author{
Review \\ Address: \\ ${ }^{1}$ Institute of Organic Chemistry, Romanian Academy, 202B Spl. \\ Independentei, POBox 35-108, Bucharest 060023, Romania, ${ }^{2}$ Petru \\ Poni Institute of Macromolecular Chemistry, Romanian Academy, lasi, \\ Romania, ${ }^{3}$ Macromolecular Chemistry and Organic Catalysis, Institute \\ of Chemistry (B6a), University of Liège, Sart Tilman, Liège 4000, \\ Belgium and ${ }^{4}$ Department of Chemistry, University of Konstanz, \\ Konstanz, Germany \\ Email: \\ lleana Dragutan* - idragutan@yahoo.com; Valerian Dragutan* - \\ vdragutan@yahoo.com; Bogdan C. Simionescu* - \\ bcsimion@icmpp.ro \\ * Corresponding author \\ Keywords: \\ advanced materials; metallopolymers; metathesis; ROMP; transition \\ metals
}

Beilstein J. Org. Chem. 2015, 11, 2747-2762. doi:10.3762/bjoc. 11.296

Received: 03 August 2015

Accepted: 30 November 2015

Published: 28 December 2015

This article is part of the Thematic Series "Progress in metathesis chemistry II".

Guest Editor: K. Grela

(C) 2015 Dragutan et al; licensee Beilstein-Institut. License and terms: see end of document.

\begin{abstract}
This account critically surveys the field of side-chain transition metal-containing polymers as prepared by controlled living ringopening metathesis polymerization (ROMP) of the respective metal-incorporating monomers. Ferrocene- and other metallocenemodified polymers, macromolecules including metal-carbonyl complexes, polymers tethering early or late transition metal complexes, etc. are herein discussed. Recent advances in the design and syntheses reported mainly during the last three years are highlighted, with special emphasis on new trends for superior applications of these hybrid materials.
\end{abstract}

\section{Introduction}

The fast growing interest in metal-containing polymers (metallopolymers) as advanced hybrid materials spurred prolific research in the worldwide organometallic and polymer scientific communities [1-4]. The variety of metals and the diversity of organic polymers allow tailoring metallopolymers so as to reach the desired physical and chemical properties suitable for progressive applications [5-7]. These functional hybrid materials are highly appreciated for their superior behaviour in catalysis, optics as well as for their magnetic, mechanical and thermal attributes. Structurally, metallopolymers are endowed with linear, cross-linked, hyperbranched, star or dendritic polymer architectures containing metals ranging from the main groups to transition metals and lanthanides which are embedded into the main chain or appended to the side chains of the polymer [8-11]. This make-up would confer an optimal set of capabilities that recommend them for diverse emerging applica- 
tion areas, e.g., as electro-optical and magnetic devices, for energy storage, nanomaterials, sensing, catalytic and drugdelivery systems [6,12-14].

Numerous synthetic routes have been explored to achieve the synthesis of these targets presently accessible through controlled and living polymerization techniques including controlled radical polymerizations (CRP) such as atom transfer radical polymerization (ATRP), nitroxide-mediated polymerization (NMP) and reversible addition-fragmentation chain transfer (RAFT) polymerization [15,16], living ionic polymerizations, specifically ring-opening polymerization (ROP) [17], as well as migration insertion polymerization (MIP) [18], acyclic diene metathesis polymerization (ADMET) $[19,20]$ and ring-opening metathesis polymerization (ROMP) [21-27]. These synthetic strategies ensure metal incorporation from the corresponding metal-containing monomers into the polymer in a precise, predetermined mode. With the advent of new metathesis catalysts endowed with a high activity and chemoselectivity and good tolerance towards many functionalities [2830], ROMP with Mo and Ru catalysts has become a very practical methodology in organic, polymer and materials chemistry. ROMP is also the method of choice for obtaining new and diverse metallopolymers [31-34].

The present contribution aims to provide an overview of selected developments in metathesis-based synthesis and applications of polymers containing transition metals in the side chain evidencing recent work published since our earlier review on this topic [34]. Metallopolymers are herein classified according to the nature of the transition metal and its binding mode to the organic moiety. Information on the physical characteristics of these materials is also included, with a focus on their present and future practical applications. Taking advantage of the considerable reactivity of ring-strained norbornenes and congeners and of their easy functionalization with many organic and organometallic groups it became possible to synthesize a broad range of polymers and copolymers by ROMP [35,36]. On the other hand it is well-known that ferrocene and numerous transition metal sandwich complexes exhibit great redox stability that allows fine tuning of their properties and applications in electrochemistry, sensing, catalysis, nanomaterials, etc. [37-40]. Not surprisingly, therefore, attention of researchers has turned first on metallopolymers containing ferrocene [33,34,41-43].

\section{Review}

\section{Iron-containing polymers}

Following the first successful application of Mo-alkylidene catalysts by Schrock and coworkers [42] in ROMP to ferroceneappended monomers as well as the rapid expansion of Grubbs $\mathrm{Ru}$ metathesis catalysts [28-30], a vast number of ironcontaining polymers have been synthesized by ROMP up to now $[33,34,42,43]$.

In a compelling work, Astruc et al. [44] reported a biologically relevant type of new homopolymers (e.g., 2, Scheme 1) and block copolymers provided with amidoferrocenyl groups linked through a tetraethylene glycol side chain. These interesting metallopolymers were readily prepared through living ROMP initiated by the Grubbs 3rd generation catalyst which proved

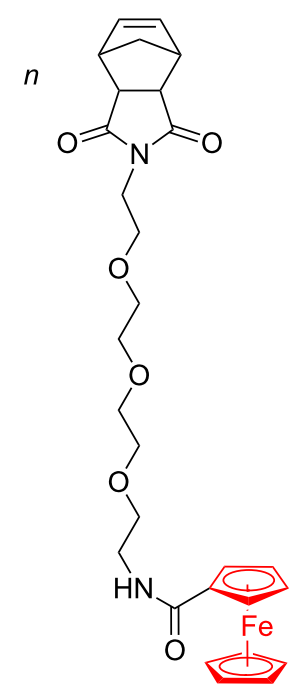

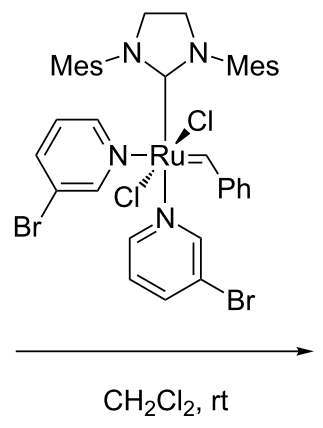

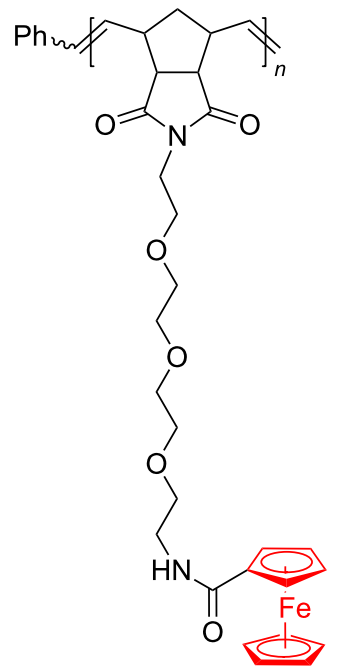

2

Scheme 1: Synthesis of homopolymers containing ferrocenyl and tetraethylene glycol groups. 
quite active and tolerant toward the monomer endowed with multiple functionalities (Scheme 1).

By precisely controlling the living polymerization process, they succeeded in varying the number of amidoferrocenyl motifs in the polymers within pre-established limits. Such polymers and block copolymers were used to prepare modified Pt electrodes with high stability and good qualitative sensing of $\mathrm{ATP}^{2-}$ anions. It was supposed that the triethylene glycol domains in the block copolymers favor the amidoferrocene-ATP interactions by encapsulation. Astruc assumed that during the recognition process different $\mathrm{H}$-bonding modes arise in the supramolecular polymeric network, i.e., an intramolecular $\mathrm{H}$ bonding with the $\beta$ - and $\gamma$-phosphate groups of $\mathrm{ATP}^{2-}$ and an intermolecular $\mathrm{H}$ bond between the $\alpha$-phosphate and another amidoferrocenyl group. Redox properties of polycationic copolymers containing the complex $\left[\mathrm{Fe}\left(\eta^{5}-\mathrm{C}_{5} \mathrm{H}_{5}\right)\left(\eta^{6}-\mathrm{C}_{6} \mathrm{Me}_{6}\right)\right]\left[\mathrm{PF}_{6}\right]$ have been recently revealed as potential electron-transfer reagents provided with a high stability [45].

On extending their research to the areas of anion sensing and nanomaterials, the Astruc group accomplished an efficient synthesis, by ROMP with Grubbs 3rd generation catalyst, of redoxrobust triazolylbiferrocenyl (trzBiFc) polymers 4 bearing the organometallic group in the side chain (Scheme 2) [46,47].

Here again, the Grubbs 3rd generation catalyst was very active and highly tolerant towards the biferrocene and triaza functionalities. Noteworthy, the oxidation of the polymer 4 with ferricenium hexafluorophosphate led to a stable biferrocenium polymer while oxidation with $\mathrm{Au}(\mathrm{III})$ or $\mathrm{Ag}(\mathrm{I})$ allowed the formation of networks with nanosnake morphology, consisting of mixed-valent $\mathrm{Fe}(\mathrm{II})-\mathrm{Fe}(\mathrm{III})$ polymers that encapsulate metal (Au or Ag) nanoparticles (NPs). These polymers were suitable for obtaining modified Pt electrodes with good sensing affinities for $\mathrm{ATP}^{2-}$ and Pd(II) cations. The importance of such results lies in the multi-electron properties of these side-chain $\mathrm{BiFc}$ polymers that have not been much studied so far although the outstanding stability of the biferrocenium motifs recommends them for designing new redox reactions, eventually leading to value-added nanomaterials. Along a different line, in a recent, inventive work Astruc and coworkers [48] demonstrated that triazolylbiferrocenyl-containing polymers can effectively stabilize palladium nanoparticles (PdNPs) affording highly active catalysts for Suzuki-Miyaura coupling reactions.

\section{Cobalt-containing polymers}

The incorporation of other late transition metals such as cobalt into polymers soon emerged as an efficient and rapid method for the production of nanostructured materials of scientific and practical importance for microelectronics, catalysis, biology and medicine (vide infra). Tang et al. [49] were the first to apply the ROMP strategy to synthesize the well-defined, high molecular weight cobaltocenium-containing polymer 6 (Scheme 3 ).

Under ambient conditions, the Grubbs 3rd generation catalyst induced polymerization of $\mathbf{5}$ in a living manner leading to a product with low polydispersity (1.12) and high molecular weight $\left(167,000 \mathrm{~g} \cdot \mathrm{mol}^{-1}\right)$. By substituting the $\mathrm{PF}_{6}{ }^{-}$anion with $\mathrm{BPh}_{4}{ }^{-}, \mathrm{Cl}^{-}$or an anion exchange resin (chloride-form), the authors demonstrated that the nature of the anion is important for the polymer properties. They found that polymer 6 was soluble in water and various organic solvents when the counteranion was chloride. Subsequently, these authors copolymer-
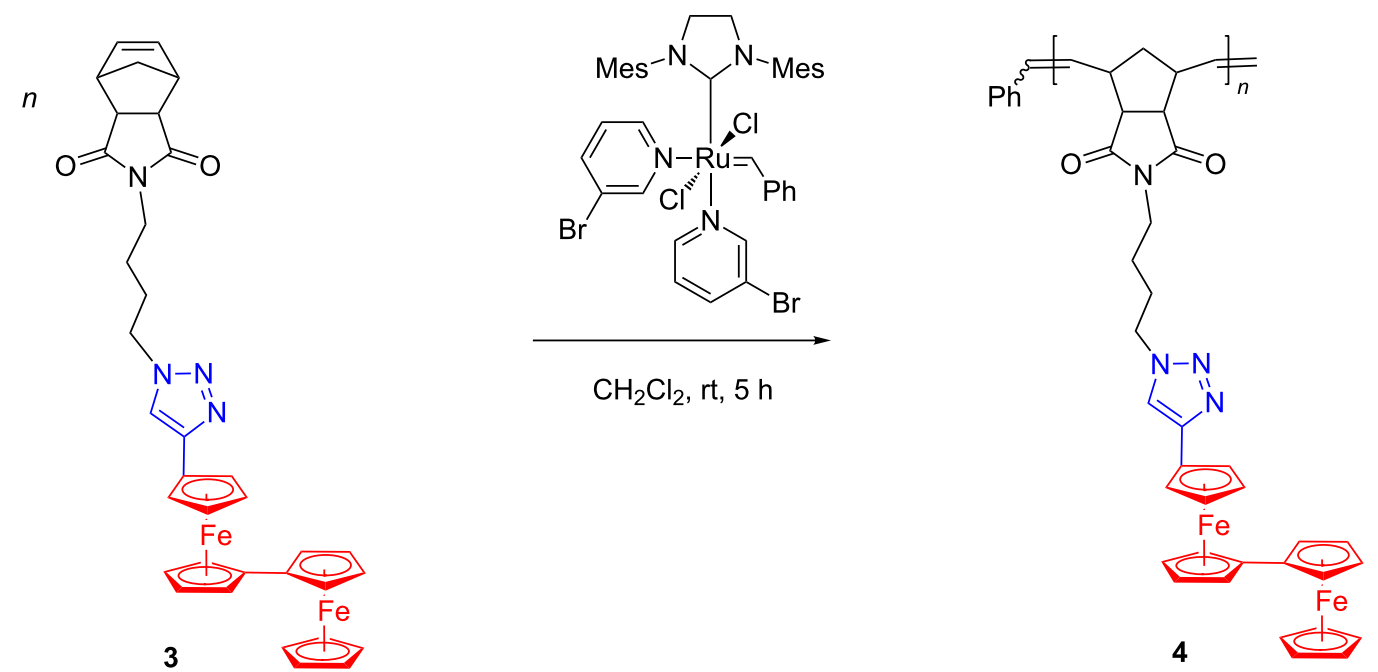

Scheme 2: Synthesis of redox-robust triazolylbiferrocenyl polymers 4 . 


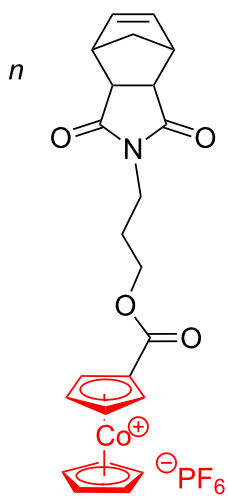

5
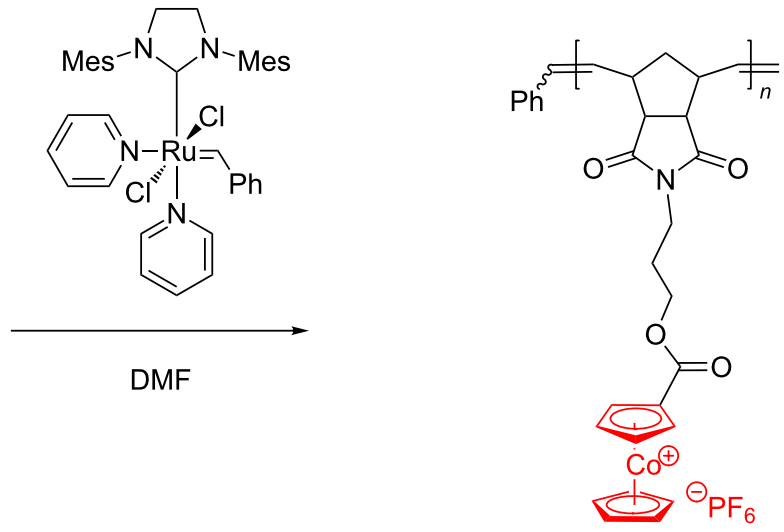

6

Scheme 3: Synthesis of cobaltocenium-containing polymers by ROMP.

ized 6 with norbornene-2-carboxylic acid, using Grubbs 3rd generation catalyst, to prepare diblock copolymer 7 , in which one block contains cobaltocenium units while the other block comprises an organic chain only [50] (Scheme 4).

By the same technique, polymer 6 was further copolymerized with a cobaltocenium- $\mathrm{BPh}_{4}$ monomer and a cobaltocenium- $\mathrm{Cl}$ monomer affording, respectively, the new diblock copolymers $\mathbf{8}$ ( $\mathrm{X}=\mathrm{PF}_{6}, \mathrm{Y}=\mathrm{BPh}_{4}$ or $\mathrm{Cl}$ ). Self-assembly of these block copolymers into core-shell spherical micelles was successfully conducted and, by UV/ozonolysis or thermal pyrolysis generating antiferromagnetic $\mathrm{CoO}$ species, some of these micelles could be converted into inorganic nanoparticles.

With the aim at extending the application of metallopolymers as heterogeneous macromolecular catalysts for living radical polymerizations, Tang et al. [51] produced the cobalt-containing polymer 10 by ROMP of the norbornene monomer $\mathbf{9}$, deriva- tized with triazolyl and cyclopentadienylcobalt-1,3-cyclopentadiene moieties (Scheme 5).

The triazolyl unit was first attached to the $\eta^{4}$-cyclopentadiene $\mathrm{CpCo}(\mathrm{I})$ complex by click reaction of the corresponding alkyne precursor and then the triazolyl-Co scaffold was incorporated into the norbornene monomer 9 by conventional esterification. It is important to note that the cyclopentadienyl-cobalt-1,3cyclopentadiene, an isoelectronic 18-electron species to ferrocene and cobaltocenium, was well tolerated by the Grubbs 3rd generation ROMP catalyst. The polymerization of 9 proceeded in a controlled and living manner under ambient conditions. Polymer 10 was successfully employed as an organometallic catalyst in the atom-transfer radical polymerization of methyl methacrylate or styrene to obtain poly(methyl methacrylate) and polystyrene devoid of colored traces of catalyst, a very important requirement for special applications, e.g., in dentistry, medical devices, housewares, and food packaging. In another

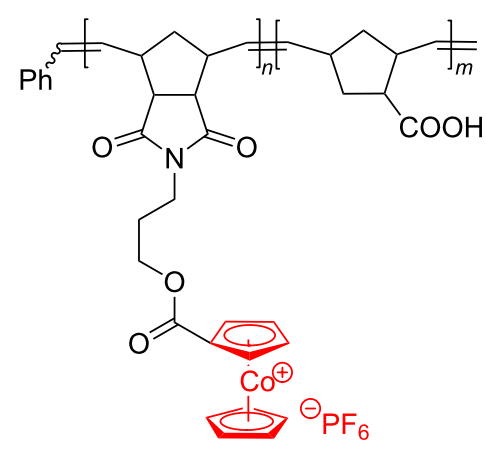

7

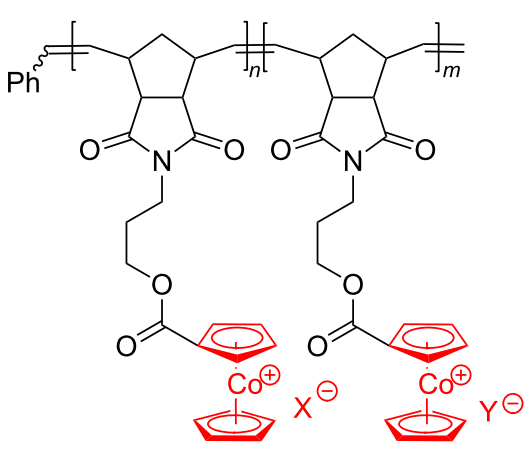

8 


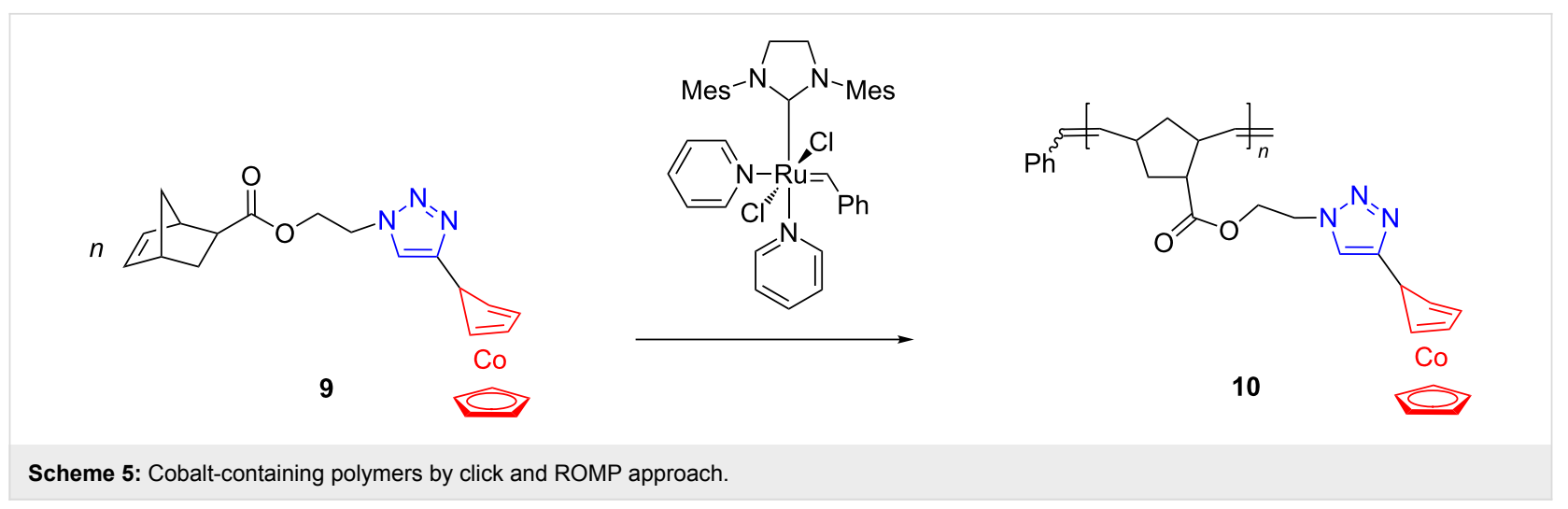

recent study, Tang and coworkers [52] performed a quantitative analysis of counterion exchange in cobaltocene-containing polyelectrolytes that are accessible by an initial ROMP, and subsequently derivatized with cobalt motifs. These results appear to be relevant for self-assembly and drug-delivery systems with this type of polyelectrolytes.

An interesting cobalt-containing diblock copolymer, bearing a dicobalt hexacarbonyl complex coordinated to an alkyne, with a constant block ratio was proposed as a new magnetic material by Tew et al. [53]. Their procedure involved the synthesis of a first block polymer, 12, by ROMP of monomer 11 using Grubbs 3 rd generation catalyst. The second block polymer was created by the addition of the cobalt-containing monomer to the reaction mixture containing 12 to continue the ROMP. Diblock copolymer 13, with a defined block ratio, could be obtained by the variation of the polymerization time (Scheme 6).

In this process, the ruthenium initiator proved to well tolerate the dicobalt hexacarbonyl complex embedded in the monomer. By controlled heating of the cobalt-containing block copolymers, robust, room temperature ferromagnetic (RTF) materials have been obtained.
By two alternative ROMP protocols, both starting from 5-formyl-2-norbornene (14) and using the Grubbs 3rd generation catalyst, Astruc and coworkers [54] successfully prepared new redox-active cobalticenium-tethered polyelectrolytes of type 17. According to the first protocol, the norbornene monomer containing an enamine-cobalticenium group (16) was first prepared by hydroamination of the ethynyl cobalticenium with $n$-butylamine-substituted norbornene $\mathbf{1 5}$. Next, 16 was polymerized to 17, by ROMP under mild conditions (Scheme 7A). In the second approach, first, the monomer $\mathbf{1 4}$ was polymerized to $17 \mathbf{a}$, followed by functionalization of the latter with $n$-butylamine to yield $\mathbf{1 7 b}$, and finally this organic polymer hydroaminated the ethynyl cobalticenium to produce 17 (Scheme 7B). Both protocols embody an elegant and original ROMP-based access to cobalticenium-containing polyelectrolytes.

\section{Ruthenium-, iridium-, osmium- and rhodium-containing polymers}

ROMP syntheses of homopolymers and block copolymers bearing bipyridine-ruthenium complexes starting from norbornene or oxanorbornene functionalized with $\mathrm{Ru}$ complexes have been reported by several authors $[55,56]$. In these investigations it was revealed that the $\mathrm{Ru}$ catalysts are active initiators

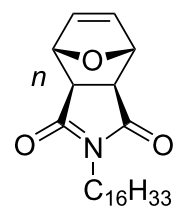

11

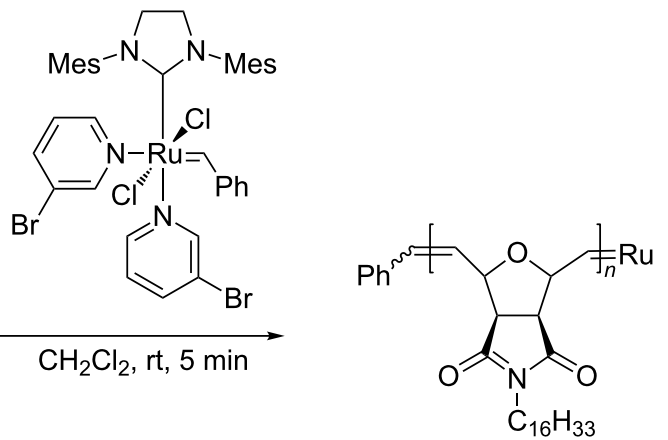

12

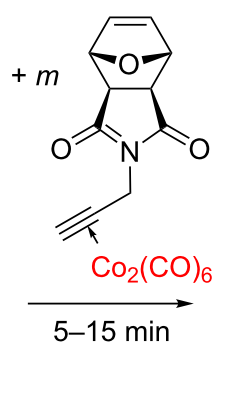

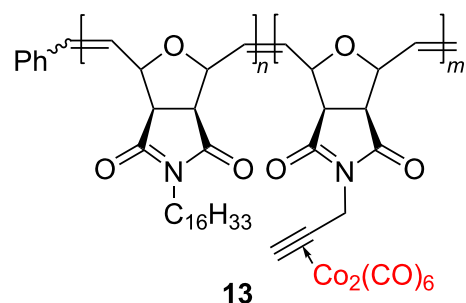

Scheme 6: Synthesis of new cobalt-integrating block copolymers. 


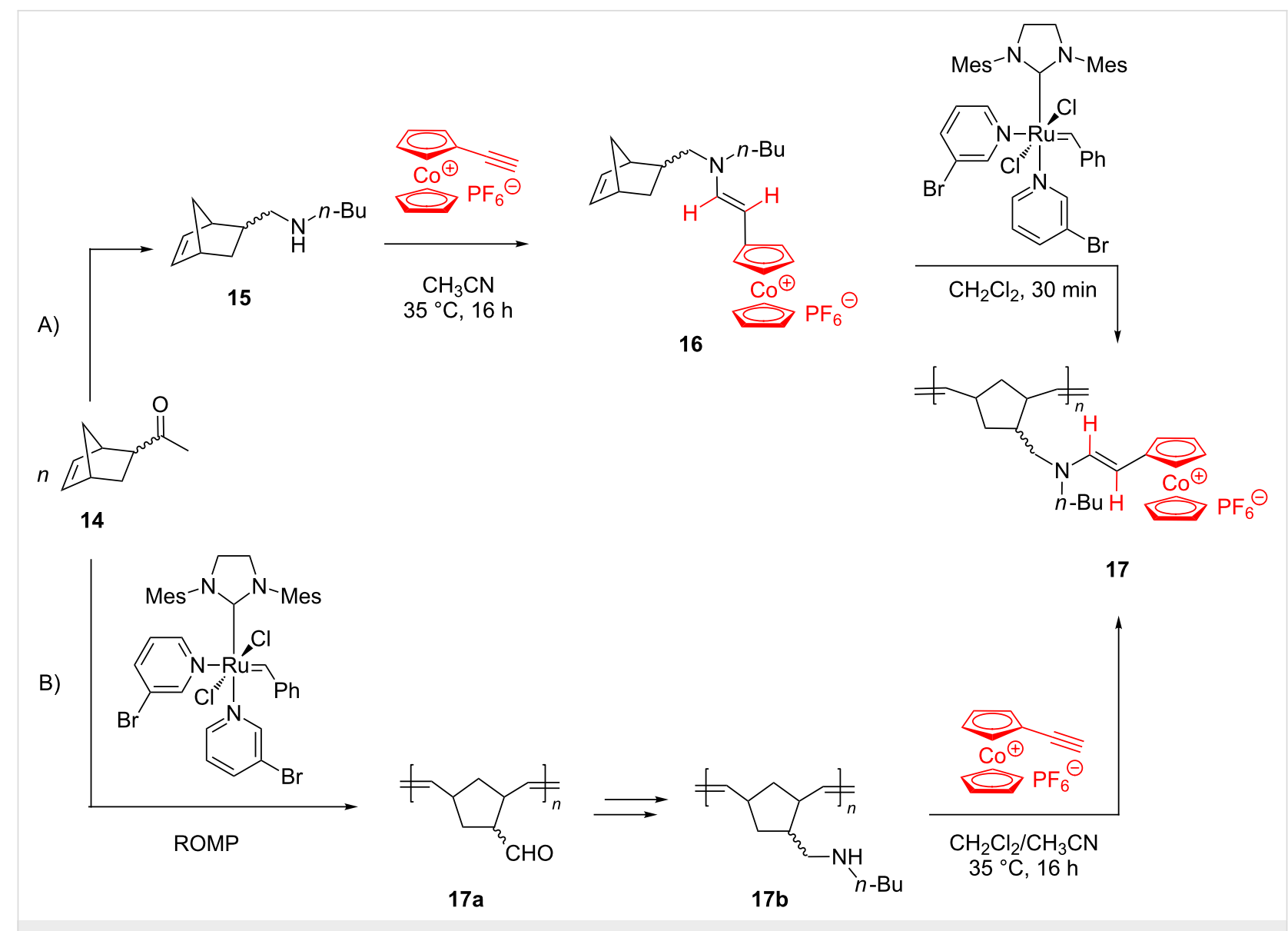

Scheme 7: Two alternative routes for the synthesis of redox-active cobalticenium-tethered polyelectrolytes.

in producing, in a living polymerization manner, well-defined polymers containing $\mathrm{Ru}$ in the side chains. Again, the best results were obtained with the Grubbs 3rd generation catalyst. Along this line, Sleiman et al. [56] prepared an array of oxanor- bornene monomers tethered with ruthenium-bipyridine motifs (e.g., 18-20, Scheme 8) and used them to prepare homopolymers (Scheme 9), diblock- (Scheme 10) and triblock copolymers (Scheme 11).<smiles></smiles><smiles></smiles><smiles></smiles> 


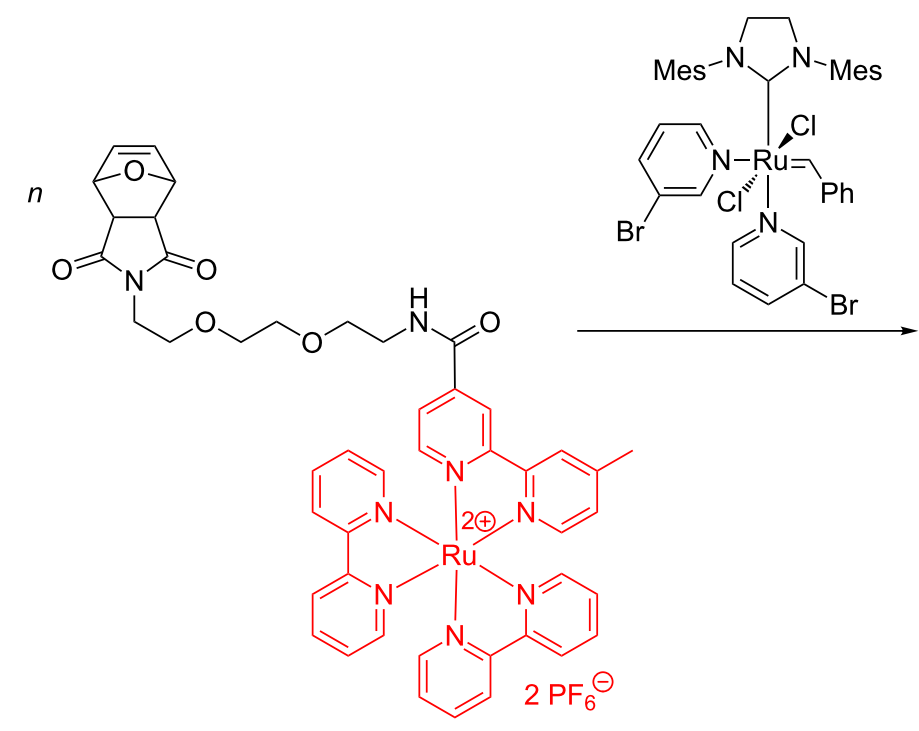

20

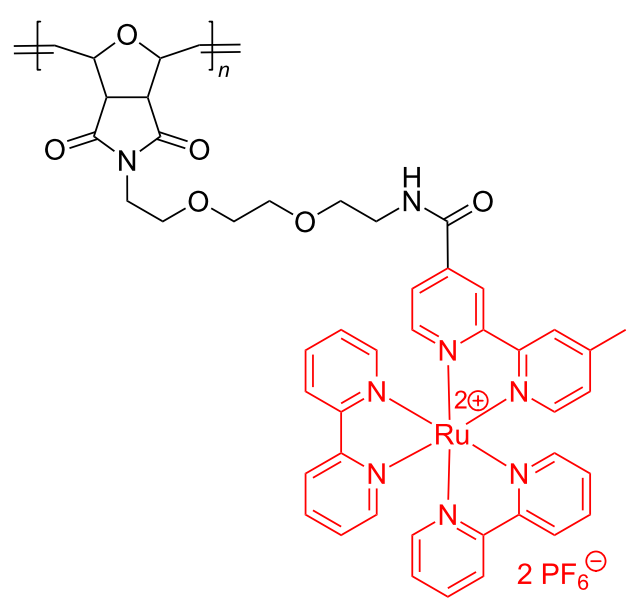

21

Scheme 9: ROMP synthesis of Ru-containing homopolymers.

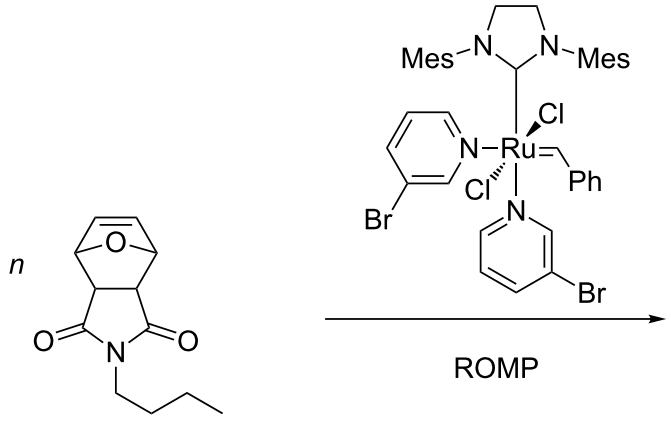

22

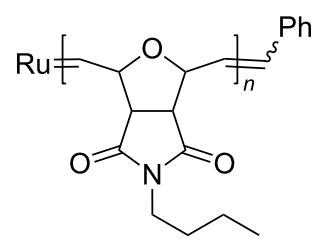

23

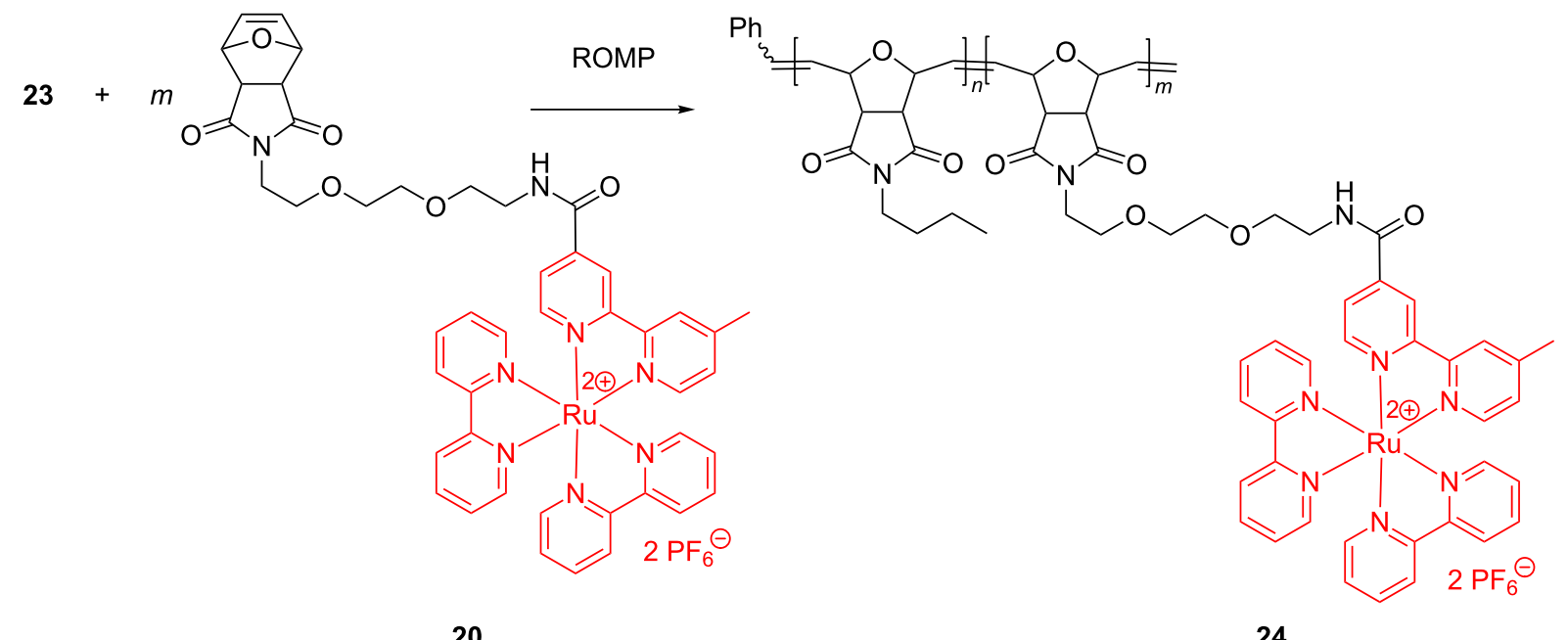

Scheme 10: Synthesis of diblock copolymers incorporating ruthenium. 

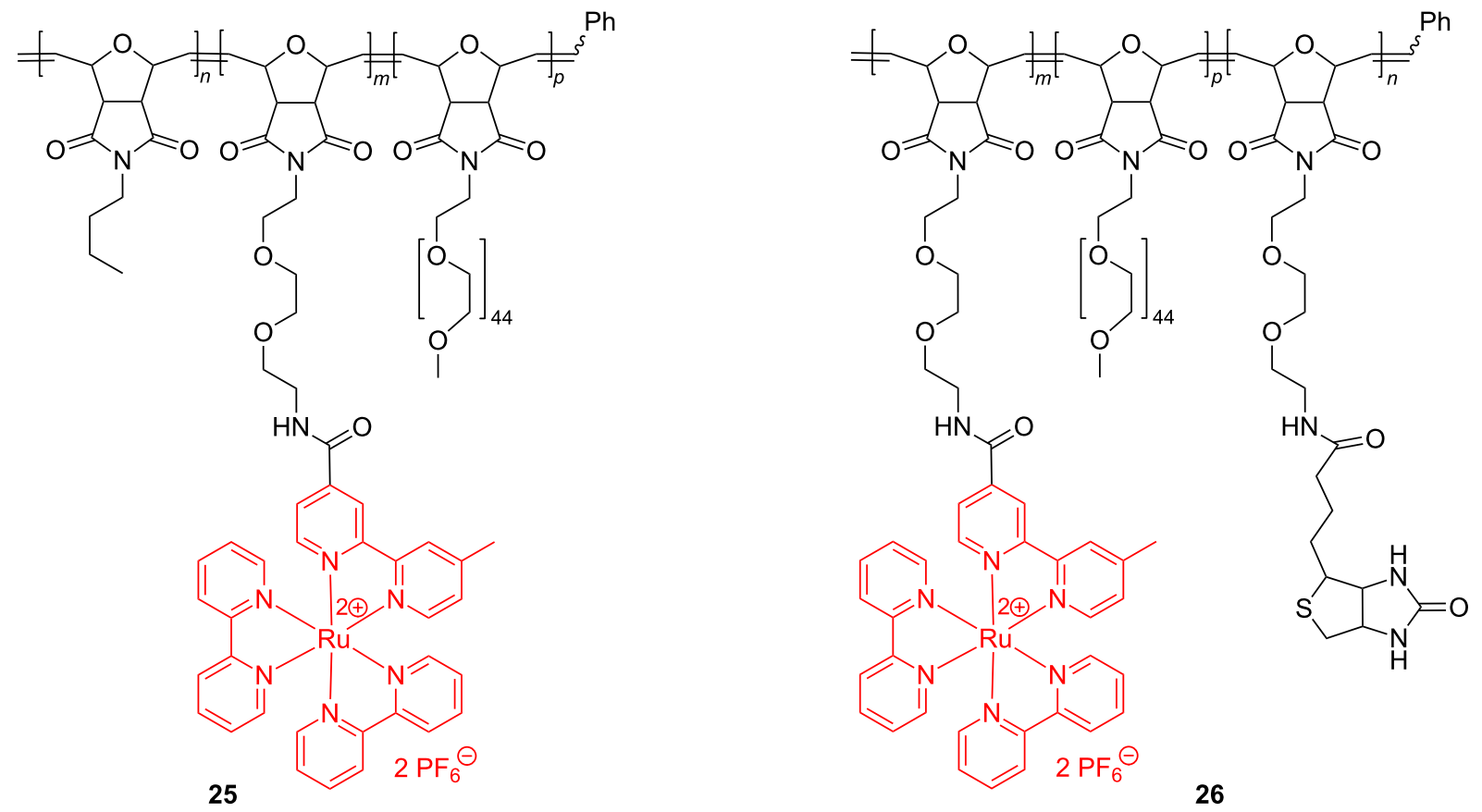

Scheme 11: Synthesis of Ru triblock copolymers.

In an in-depth exploration of the synthesis of diblock copolymers 24, Sleiman developed a step-wise procedure: in the first step, the ruthenium catalyst induced polymerization of the bicyclic monomer $\mathbf{2 2}$ to homopolymer $\mathbf{2 3}$, followed by polymerization of the additional comonomer $\mathbf{2 0}$ at the Ru site of $\mathbf{2 3}$ to yield the copolymer 24 (Scheme 10).

Based on their potential application as tools for biological detection and signal amplification, amphiphilic Ru-modified triblock copolymers have been produced from biocompatible and bioconjugatable oxanorbornene monomers. By extending the above ROMP methodology, Sleiman et al. managed to synthesize the Ru triblock copolymers $\mathbf{2 5}$ and $\mathbf{2 6}$ (Scheme 11), and examined their self-assembling into micelles in aqueous media to evaluate them as luminescent markers of biological molecules.

The production of metal-cation-based anion exchange membranes from ROMP polymers was first reported by Tew et al. [57]. The ROMP reaction, induced here by the Grubbs 2nd generation catalyst, implied the copolymerization of a norbornene monomer (27) functionalized with a water-soluble bis(terpyridine)ruthenium(II) complex, with dicyclopentadiene as a cross-linking agent (Scheme 12). In the resulted copolymer

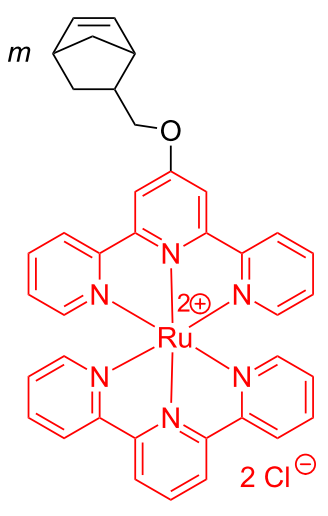

27
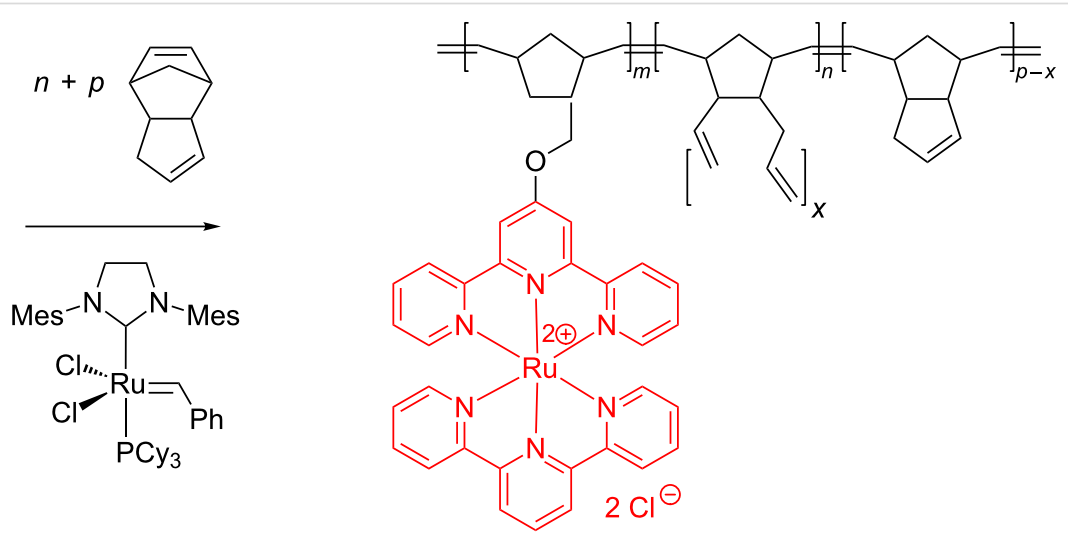

28

Scheme 12: Synthesis of cross-linked Ru-containing triblock copolymers. 
28 each Ru complex is associated with two counteranions (chloride), which represents a novelty versus most cation-based membranes provided with single cation-anion pairs. Crosslinking with dicyclopentadiene ensured a high mechanical stability of the copolymer. The film cast from $\mathbf{2 8}$ displayed an anion conductivity and mechanical properties similar to those of the traditional quaternary ammonium-based anion exchange membranes. In addition, the film exhibited high methanol and base tolerance making it suitable for applications in fuel cells and anion-conducting devices.

Owing to their high phosphorescent propensity, complexes based on iridium have been grafted onto polymers for the application as light-emitting diodes (LEDs) [58]. In an earlier research, in order to obtain iridium-containing polymers by the ROMP route, Weck and coworkers [59] polymerized monomers 29 and mer-31, in the presence of Grubbs 3rd generation catalyst, to the fully soluble ROMP homopolymers $\mathbf{3 0}$ and mer-32 (Scheme 13).

Later on, while investigating the self-assembly of transition metal-containing polymers, Sleiman et al. [60] expanded the field by preparing ROMP-able oxanorbornene monomers having iridium and osmium bipyridines attached by an extended organic linker (Scheme 14).

The triblock copolymers obtained through a sequential ROMP of the corresponding monomers, appended to Ir bipyridine

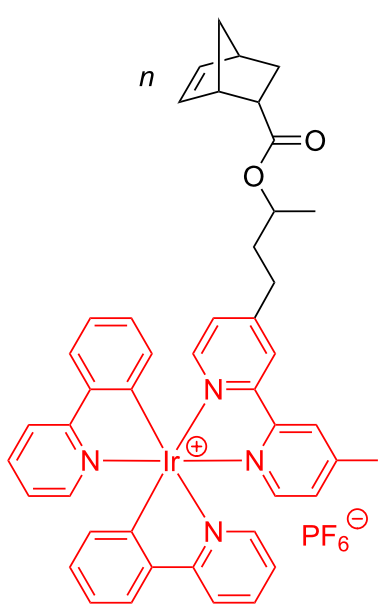

29

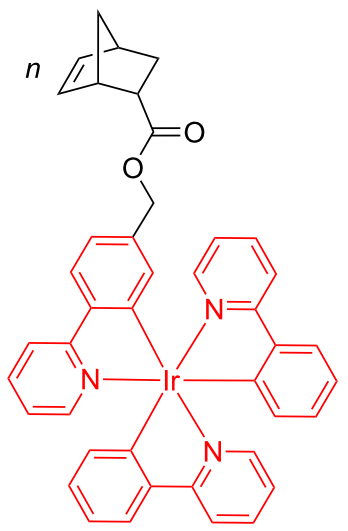

mer-31
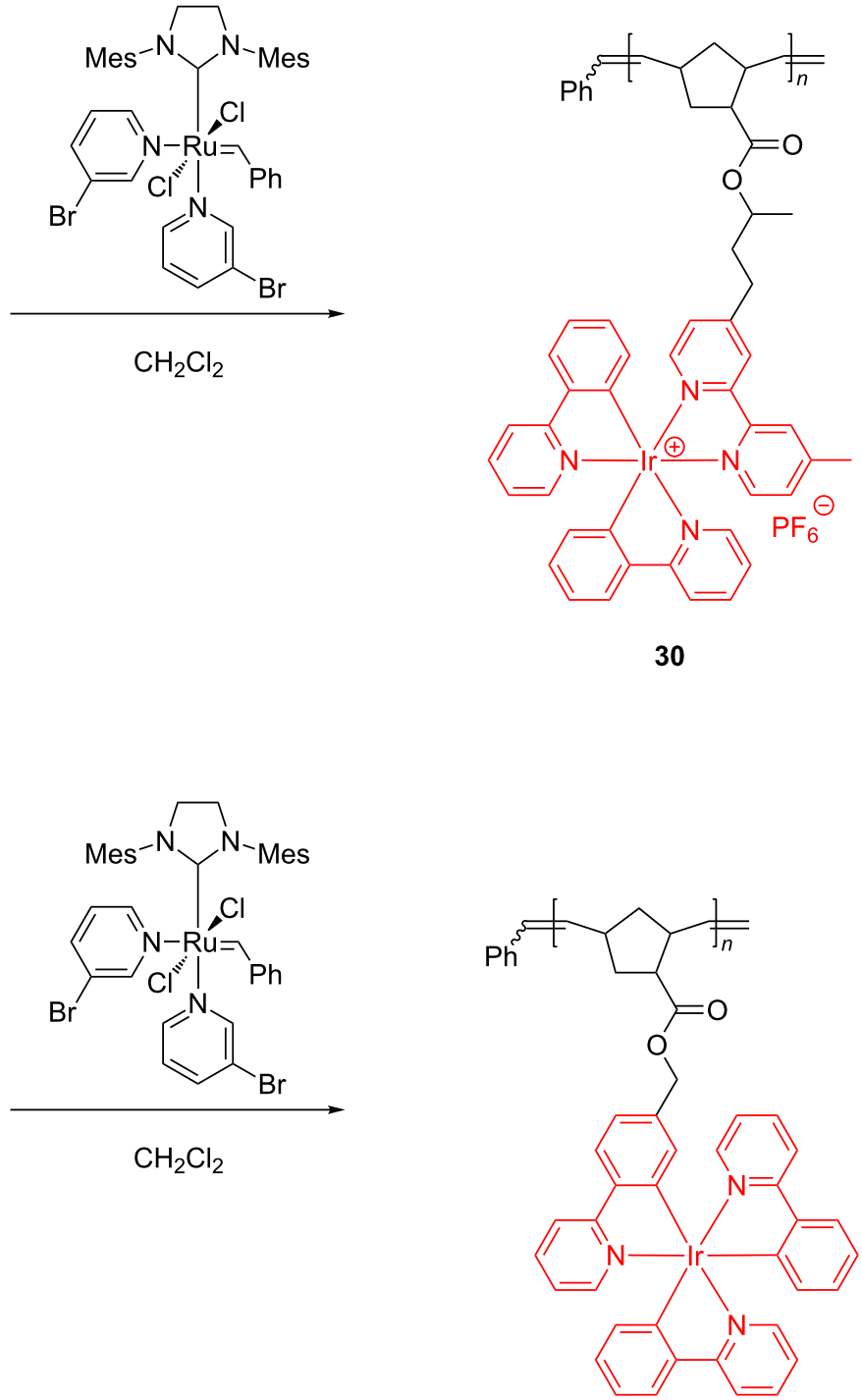

mer-32 


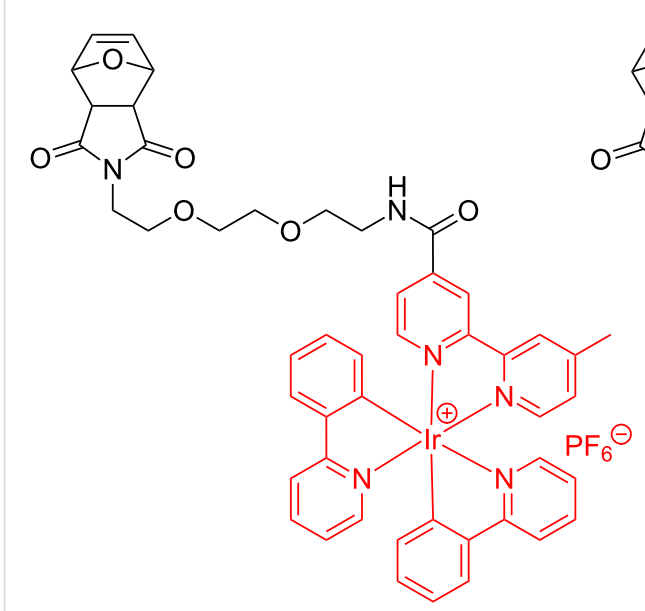

33

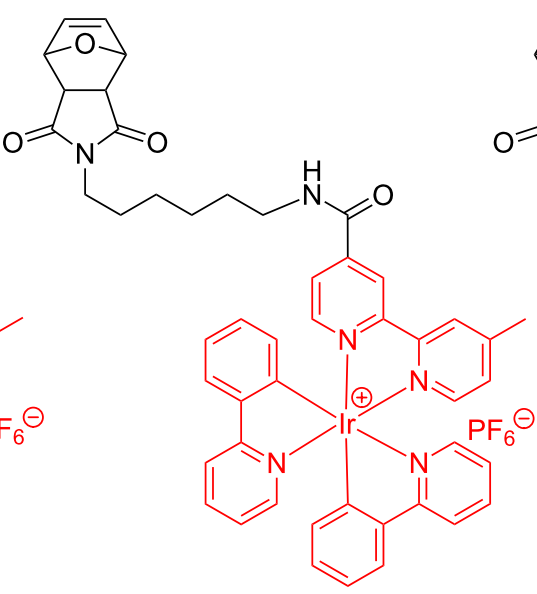

34

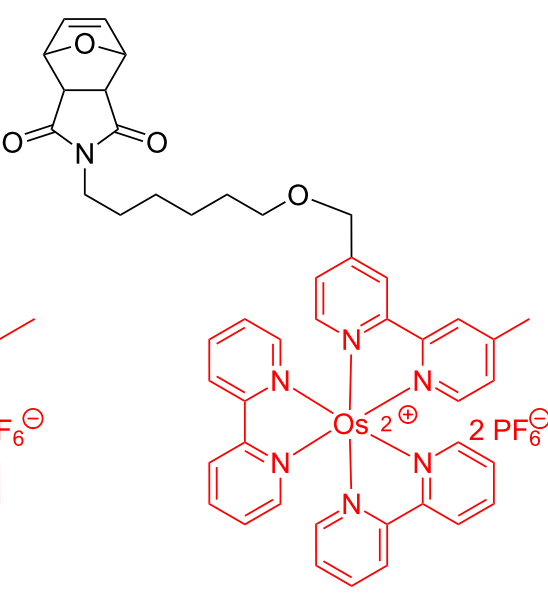

35

Scheme 14: Monomers for Ir- and Os-containing ROMP polymers.

complexes, oligoethylene glycol and biotin entities, have been examined by fluorescence spectroscopy for their self-assembling behavior and biodetection capability (Scheme 15).

In a very interesting work, Blechert, Buchmeiser and coworkers [61] copolymerized norborn-5-ene-( $N, N$-dipyrid-2-yl)carbamide with exo,exo-[2-(3-ethoxycarbonyl-7-oxabicyclo[2.2.1]hept-5en-2-carbonyloxy)ethyl]trimethylammonium iodide to polymer
38, using the Schrock Mo catalyst. By further reaction with $[\mathrm{Rh}(\mathrm{COD}) \mathrm{Cl}]_{2}(\mathrm{COD}=$ cycloocta-1,5-diene), polymer 38 gave the $\mathrm{Rh}(\mathrm{I})$-appended block copolymer 39 (Scheme 16).

Remarkably, in water, this Rh-containing block copolymer readily generated micelles and could be thus successfully employed as a Rh-immobilized catalyst for the hydroformylation of 1-octene.

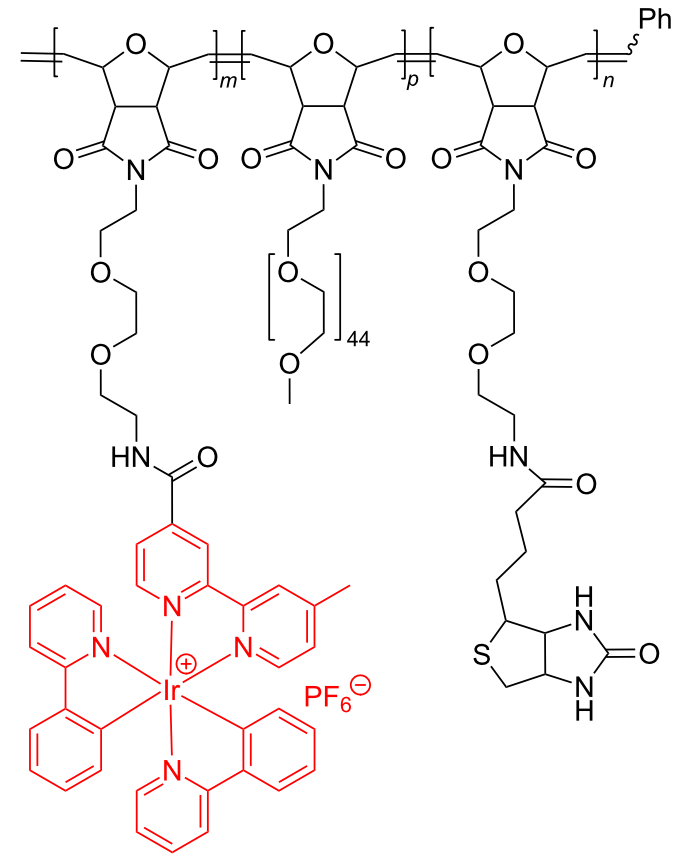

36

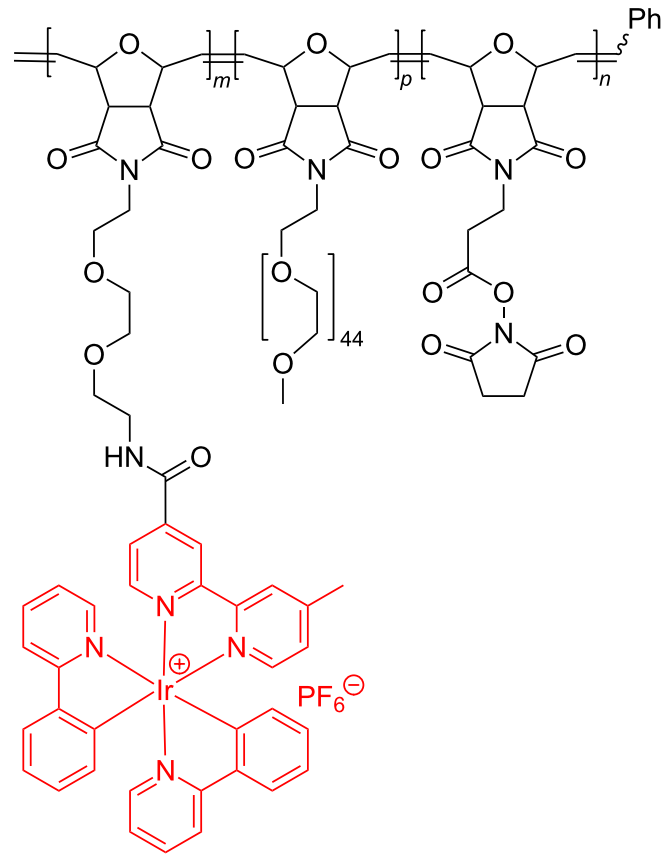

37

Scheme 15: ROMP block copolymers integrating Ir in their side chains. 


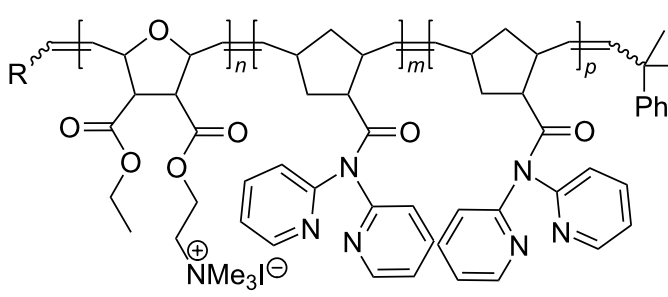

38

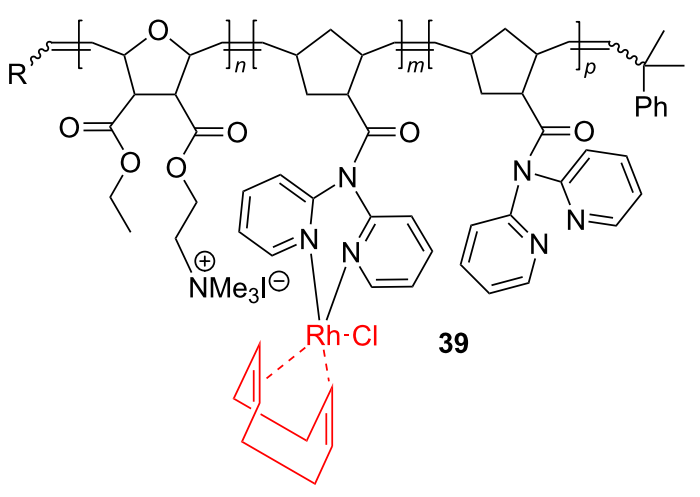

Scheme 16: Synthesis of Rh-containing block copolymers.

Very recently, Matyjaszewski, Tang and coworkers [62] reported the first synthesis of norbornene monomers substituted with rhodocenium units and their controlled polymerization, by two parallel routes (ROMP and RAFT), to rhodoceniumcontaining metallopolymers. ROMP of both triazolyl-rhodocenium monomers, $\mathbf{4 0}$ and $\mathbf{4 2}$, proceeded productively and in a living fashion to yield amphiphilic metallopolymers $\mathbf{4 1}$ and $\mathbf{4 3}$ (Scheme 17).
Polymers $\mathbf{4 1}$ and $\mathbf{4 3}$ have been evaluated for their counterion exchange properties and self-assembling tendency revealing a promising application profile. The point of interest here is that rhodocenium exhibits different chemical and physical properties from cobaltocenium. A novel immobilized Rh catalytic system in which the metal is embedded, by means of the 5,5-dinorimido BINAP ligand, into the polymer, obtained from alternating ROMP of cyclooctene with the Grubbs first $n$<smiles>O=C(OCCn1cc(C2C=CC2)nn1)C1CC2C=CC1C2</smiles>

40<smiles>O=C(OCCn1cc(-c2cccc([R](F)(F)F)c2)nn1)C1CC2C=CC1C2</smiles>

42

$\mathrm{Rh}$

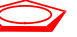

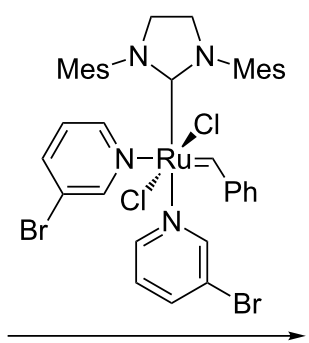

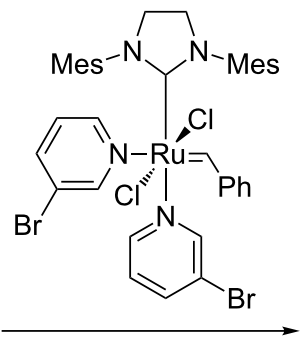

43<smiles>CC(C)(C)C1CC(C(=O)OCCn2cc(C3C=CC3)nn2)C(C(C)(C)C)C1</smiles>

41

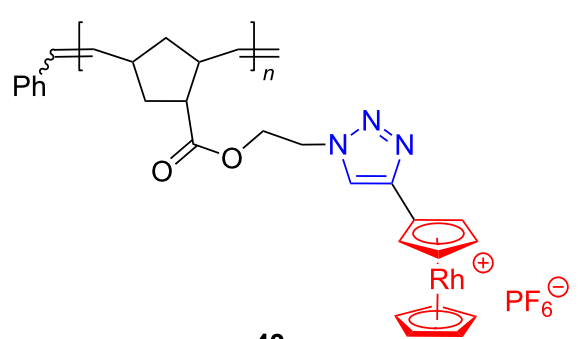


generation catalyst, has been disclosed in a patent by Bergens et al. [63]. This catalytic system allowed the intramolecular cycloisomerization of enynes with high yields and turnover numbers.

\section{Copper-containing polymers}

A copper(I) complex containing a norbornene substituted with the 2-(pyridin-2-yl)-1H-benzimidazole ligand, $\mathbf{4 4}$, developed by
Il'icheva et al. [64], came to the attention of the scientific community involved in the area. The complex was used to access $\mathrm{Cu}$-containing homopolymers $\mathbf{4 5}$ and copolymers 47 under metathesis polymerization with the Grubbs 3rd generation catalyst (Scheme 18 and Scheme 19). Further variations in the spacer subunit from a norbornene carbazole comonomer $\mathbf{4 6}$ enabled fine-tuning of the physical and chemical properties of the copolymer 47.

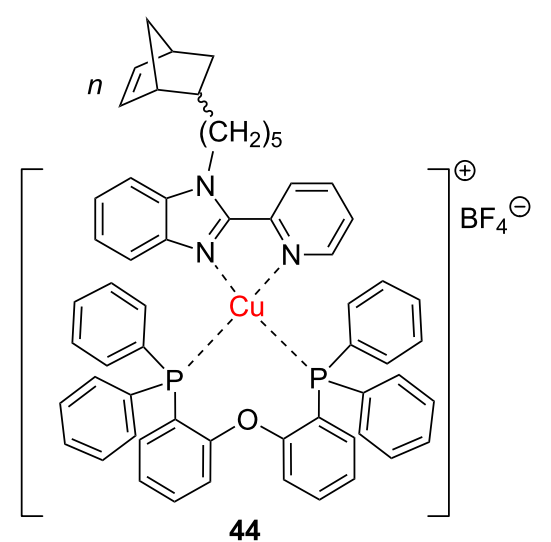

44

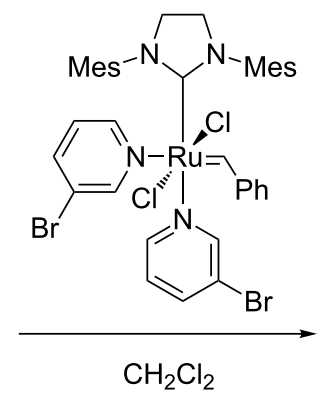

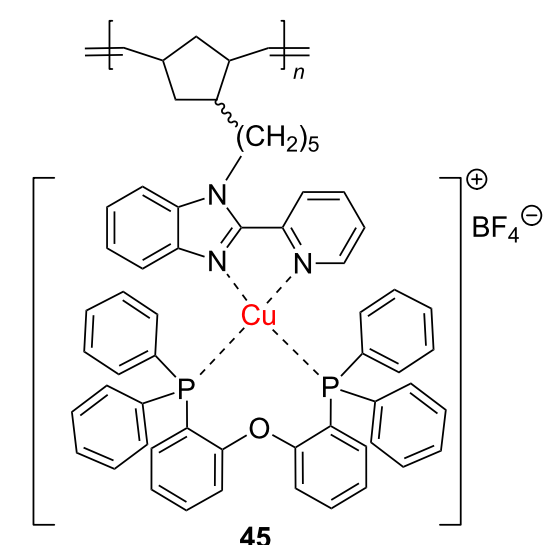

Scheme 18: Synthesis of homopolymers equipped with Cu coordination centers.<smiles>c1ccc2c(c1)c1ccccc1n2C1CCC1C1CC2CCC1C2</smiles>

46<smiles>CC(C)(C)C1CC2CCC(C3CCC3)C2C12CCC(n1c3ccccc3c3ccccc31)C2</smiles>

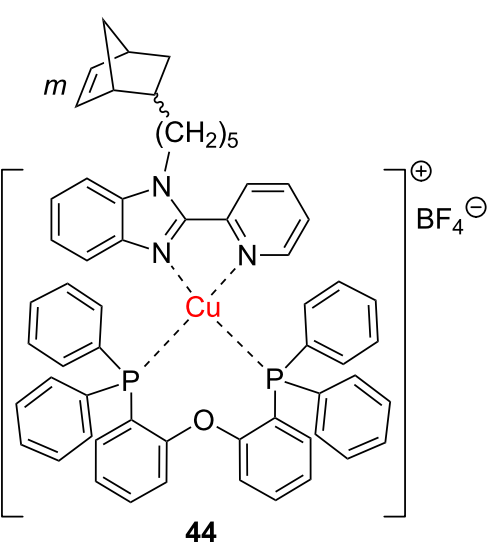

44



Scheme 19: Synthesis of Cu-containing copolymers (spacer $\left.=-\left(\mathrm{CH}_{2}\right)_{5}-;>\mathrm{C}=\mathrm{O}\right)$. 
These materials, in which $\mathrm{Cu}$ is tethered to the polymeric backbone by an organic linker, exhibited notable luminescent characteristics. The same research group subsequently introduced other new copper(I) complexes, ligating norbornene-substituted phenanthroline, that were polymerized by ROMP (Grubbs 3rd generation catalyst) to yield copolymers with valuable photoand electroluminescent properties [65]. This kind of hybrid structure may induce high performance in LED devices.

\section{Early transition metal-containing polymers}

In contrast to the numerous polymers including late transition metals discussed so far, only few representatives of early transition metals attached to ROMP polymers have been disclosed recently. Thus, Wang et al. [66] communicated the ROMP synthesis of the first polynorbornene bearing a polyoxometalate (POM) cluster in the side chain (Scheme 20).

According to their concept, the norbornene monomer containing a trivanadium-substituted Wells-Dawson-type polyoxotungstate (POM) (48) was polymerized quantitatively to 49 in a living and controlled process under promotion of Grubbs 3rd generation catalyst. It should be remarked that this Grubbs catalyst favored the polymerization under mild reaction conditions and tolerated very well the bulky POM cluster attached to the monomer. The obtained hybrid materials are promising candidates for the production of high-performance catalysts based on poly(polyoxometalate)s.

\section{Lanthanide-containing polymers}

Recently, new polynorbornenes of type 53, functionalized with terpyridine and carbazole moieties and integrating a europium complex in the pendant chains, were described by Rozhkov et al. [67]. They were obtained by a metathesis copolymerization with Grubbs 3rd generation catalyst as the key step (Scheme 21).

In a first approach the copolymer $\mathbf{5 2}$ was coordinated with europium thenoyl trifluoroacetonate to yield copolymers $\mathbf{5 3}$ with different ratios between the purely organic and europiumcontaining units. Alternatively, similar coordination copolymers were prepared by copolymerizing the europium complex of the terpyridine monomer $\mathbf{5 1}$ with the carbazole-substituted norbornene 50. In solution or in thin film these Eu-containing products exhibited important metal-centered photoluminescence recommending them for novel applications.

Unveiling and rationalizing the interactions between the metal and the organic polymer backbone and/or side chains is crucial for ensuring the desired properties for the hybrid material [68]. Indeed, when appraising luminescence of a series of polynorbornenes attaching various homoleptic bi- or trinuclear lanthanide salen complexes (with $\mathrm{La}, \mathrm{Nd}, \mathrm{Yb}, \mathrm{Er}, \mathrm{Gd}$ or Tb), Lü et al. $[69,70]$ established that, only in the case of $\mathrm{Nd}$ and $\mathrm{Yb}$ metallopolymers, the luminescent emissions are strongly retained versus those of the respective monomers in solution.

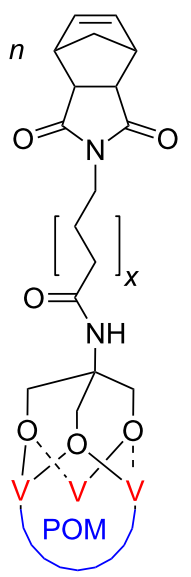

48
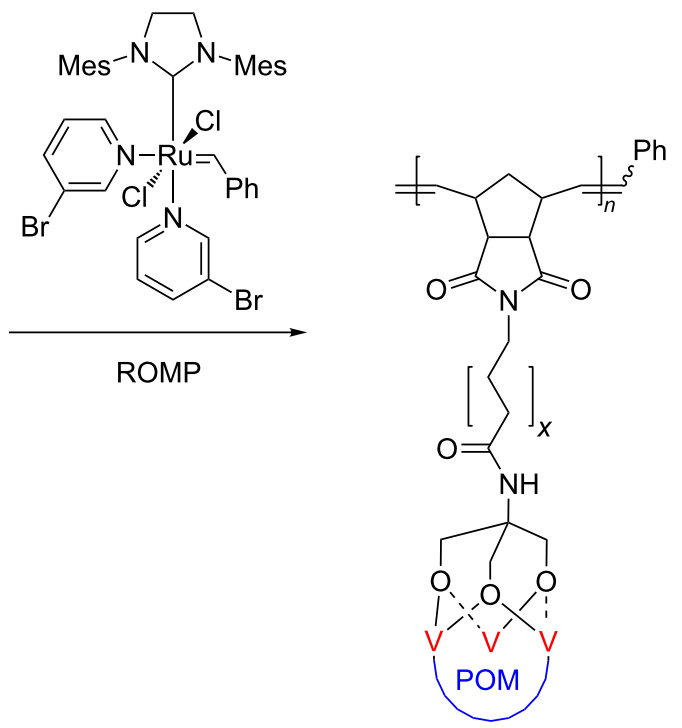

49 
$n$<smiles>O=C([C@@H]1C[C@H]2CC[C@H]1C2)n1c2ccccc2c2ccccc21</smiles>

50

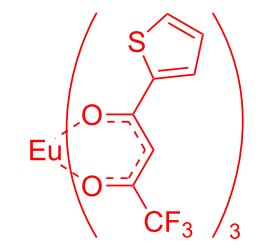

$\mathrm{CH}_{2} \mathrm{Cl}_{2}$<smiles>O=C(Oc1cc(-c2ccccn2)nc(-c2ccccn2)c1)[C@H]1C[C@@H]2CC[C@H]1C2</smiles>

51

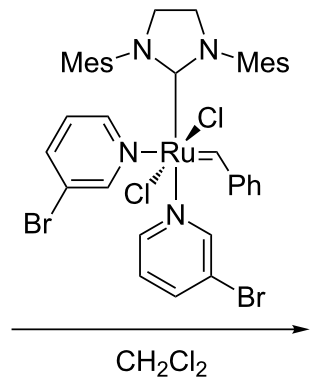<smiles>C#CC1CC(C#C)C(C(=O)n2c3ccccc3c3ccccc32)C1C(=O)Oc1cc(-c2ccccn2)nc(-c2ccccn2)c1</smiles>

52

Scheme 21: Synthesis of Eu-containing copolymers by a ROMP-based route.

\section{Conclusion}

This review highlights ingenious ways in which a large variety of transition metals could be attached to organic polymer sidechains thus prompting the appearance of extraordinary new physical properties (optical, electrical, conducting, catalytic, magnetic, biological, etc.), most of which were not detained before by either the metal or the organic counterpart. Such distinguishing features recommend these privileged scaffolds as important hybrid materials having a strong impact on a host of current high-tech applications, as fuel cells, light-emitting diodes (LED), magnetic nanomaterials, catalysts, biosensors, for energy generation and storage. The mainstay of the synthesis of these engineered metallopolymers is living ROMP, the key step advantageously executed either with Schrock's or Grubbs latest generation catalysts, and easier to be precisely controlled versus other techniques used for the preparation of metallopolymers.

\section{Acknowledgements}

The authors gratefully acknowledge support from the Romanian Academy and Ministry of Education and Research, as well as from Wallonie-Bruxelles International (WBI), the Direction générale des Relations extérieures de la Région wallonne, and the Fonds de la Recherche scientifique. Special thanks are due to the Referees and to the Editors of the Beilstein Journal of Organic Chemistry for their helpful comments and suggestions.

\section{References}

1. Manners, I. Synthetic Metal Containing Polymers; Wiley-VCH: Weinheim, Germany, 2004. doi:10.1002/3527601686

2. Abd-El-Aziz, A. S.; Manners, I., Eds. Frontiers in Transition Metal Containing Polymers; John Wiley \& Sons: Hoboken, New Jersey, USA, 2007.

3. Russell, A. D.; Musgrave, R. A.; Stoll, L. K.; Choi, P.; Quu, H.; Manners, I. J. Organomet. Chem. 2015, 784, 24-30. doi:10.1016/j.jorganchem.2014.10.038 
4. Abd-El-Aziz, A. S.; Agatemor, C.; Etkin, N. Macromol. Rapid Commun. 2014, 35, 513-559. doi:10.1002/marc. 201300826

5. Schacher, F. H.; Rupar, P. A.; Manners, I. Angew. Chem., Int. Ed. 2012, 51, 7898-7921. doi:10.1002/anie.201200310

6. Whittell, G. R.; Hager, M. D.; Schubert, U. S.; Manners, I. Nat. Mater. 2011, 10, 176-188. doi:10.1038/nmat2966

7. Breul, A. M.; Kübel, J.; Häupler, B.; Friebe, C.; Hager, M. D.; Winter, A.; Dietzek, B.; Schubert, U. S. Macromol. Rapid Commun. 2014, 35, 747-751. doi:10.1002/marc.201300806

8. Cao, K.; Murshid, N.; Wang, X. Macromol. Rapid Commun. 2015, 36, 586-596. doi:10.1002/marc.201400563

9. Rapakousiou, A.; Djeda, R.; Grillaud, M.; Li, N.; Ruiz, J.; Astruc, D. Organometallics 2014, 33, 6953-6962. doi:10.1021/om501031u

10. Mavila, S.; Diesendruck, C. E.; Linde, S.; Amir, L.; Shikler, R.; Lemcoff, N. G. Angew. Chem., Int. Ed. 2013, 52, 5767-5770. doi:10.1002/anie.201300362

11. Dragutan, V.; Dragutan, I.; Fischer, $\mathrm{H}$. J. Inorg. Organomet. Polym. Mater. 2008, 18, 18-31. doi:10.1007/s10904-007-9185-5

12. Mavila, S.; Rozenberg, I.; Lemcoff, N. G. Chem. Sci. 2014, 5 , 4196-4203. doi:10.1039/c4sc01231c

13. Abd-El-Aziz, A. S.; Strohm, E. A. Polymer 2012, 53, 4879-4921. doi:10.1016/j.polymer.2012.08.024

14. Eloi, J.-C.; Chabanne, L.; Whittell, G. R.; Manners, I. Mater. Today 2008, 11, 28-36. doi:10.1016/S1369-7021(08)70054-3

15. Yan, Y.; Zhang, J.; Qiao, Y.; Ganewatta, M.; Tang, C. Macromolecules 2013, 46, 8816-8823. doi:10.1021/ma402039u

16. Hadadpour, M.; Gwyther, J.; Manners, I.; Ragogna, P. J. Chem. Mater. 2015, 27, 3430-3440. doi:10.1021/acs.chemmater.5b00752

17. Baljak, S.; Russell, A. D.; Binding, S. C.; Haddow, M. F.; O’Hare, D.; Manners, I. J. Am. Chem. Soc. 2014, 136, 5864-5867. doi:10.1021/ja5014745

18. Wang, X.; Cao, K.; Liu, Y.; Tsang, B.; Liew, S. J. Am. Chem. Soc. 2013, 135, 3399-3402. doi:10.1021/ja400755e

19. Ding, L.; Wang, C.; Lin, L.; Zhu, Z. Macromol. Chem. Phys. 2015, 216, 761-769. doi:10.1002/macp.201400579

20. Bachler, P. R.; Wagener, K. B. Monatsh. Chem. 2015, 146, 1053-1061. doi:10.1007/s00706-015-1479-7

21. Autenrieth, B.; Jeong, H.; Forrest, W. P.; Axtell, J. C.; Ota, A.; Lehr, T.; Buchmeiser, M. R.; Schrock, R. R. Macromolecules 2015, 48, 2480-2492. doi:10.1021/acs.macromol.5b00123

22. Dragutan, I.; Dragutan, V.; Demonceau, A. Molecules 2015, 20 , 17244-17274. doi:10.3390/molecules200917244

23. Rosebrugh, L. E.; Marx, V. M.; Keitz, B. K.; Grubbs, R. H. J. Am. Chem. Soc. 2013, 135, 10032-10035. doi:10.1021/ja405559y

24. Elling, B. R.; Xia, Y. J. Am. Chem. Soc. 2015, 137, 9922-9926. doi:10.1021/jacs.5b05497

25. Eissa, A. M.; Khosravi, E. Macromol. Chem. Phys. 2015, 216, 964-976. doi:10.1002/macp.201400604

26. Dragutan, V.; Dragutan, I.; Dimonie, M. Tuning Product Selectivity in ROMP of Cycloolefins with W-Based Catalytic Systems. In Green Metathesis Chemistry: Great Challenges in Synthesis, Catalysis and Nanotechnology; Dragutan, V.; Demonceau, A.; Dragutan, I.; Finkelshtein, E. S., Eds.; Springer-Verlag: New York, 2010; pp 383-390. doi:10.1007/978-90-481-3433-5_24

27. Gutekunst, W. R.; Hawker, C. J. J. Am. Chem. Soc. 2015, 137, 8038-8041. doi:10.1021/jacs.5b04940

28. Grubbs, R. H.; Wenzel, A. G.; O'Leary, D. J.; Khosravi, E., Eds. Handbook of Metathesis, 2nd ed.; Wiley-VCH: Weinheim, Germany, 2015.
29. Grela, K. Beilstein J. Org. Chem. 2010, 6, 1089-1090. doi:10.3762/bjoc.6.124

30. Levin, E.; Mavila, S.; Eivgi, O.; Tzur, E.; Lemcoff, N. G. Angew. Chem., Int. Ed. 2015, 54, 12384-12388. doi:10.1002/anie.201500740

31. Zeits, P. D.; Fiedler, T.; Gladysz, J. A. Chem. Commun. 2012, 48, 7925-7927. doi:10.1039/C2CC32150E

32. Wappel, J.; Grudzień, K.; Barbasiewicz, M.; Michalak, M.; Grela, K.; Slugovc, C. Monatsh. Chem. 2015, 146, 1153-1160. doi:10.1007/s00706-015-1494-8

33. Hardy, C. G.; Zhang, J.; Yan, Y.; Ren, L.; Tang, C. Prog. Polym. Sci. 2014, 39, 1742-1796. doi:10.1016/j.progpolymsci.2014.03.002

34. Dragutan, I.; Dragutan, V.; Fischer, H. J. Inorg. Organomet. Polym. Mater. 2008, 18, 311-324. doi:10.1007/s10904-008-9213-0

35. Yampolskii, Yu.; Starannikova, L.; Belov, N.; Bermeshev, M.; Gringolts, M.; Finkelshtein, E. J. Membr. Sci. 2014, 453, 532-545. doi:10.1016/j.memsci.2013.11.002

36. Bang, A.; Mohite, D.; Saeed, A. M.; Leventis, N.; Sotiriou-Leventis, C. J. Sol-Gel Sci. Technol. 2015, 75, 460-474. doi:10.1007/s10971-015-3718-0

37. Hardy, C. G.; Ren, L.; Ma, S.; Tang, C. Chem. Commun. 2013, 49, 4373-4375. doi:10.1039/c2cc36756d

38. Zhou, J.; Whittell, G. R.; Manners, I. Macromolecules 2014, 47, 3529-3543. doi:10.1021/ma500106x

39. Zha, Y.; Thaker, H. D.; Maddikeri, R. R.; Gido, S. P.; Tuominen, M. T.; Tew, G. N. J. Am. Chem. Soc. 2012, 134, 14534-14541. doi:10.1021/ja305249b

40. AL-Badri, Z. M.; Maddikeri, R. R.; Zha, Y.; Thaker, H. D.; Dobriyal, P.; Shunmugam, R.; Russell, T. P.; Tew, G. N. Nat. Commun. 2011, 2, 482. doi:10.1038/ncomms 1485

41. Hardy, C. G.; Ren, L.; Zhang, J.; Tang, C. Isr. J. Chem. 2012, 52, 230-245. doi:10.1002/ijch.201100110

42. Albagli, D.; Bazan, G.; Wrighton, M. S.; Schrock, R. R. J. Am. Chem. Soc. 1992, 114, 4150-4158. doi:10.1021/ja00037a017

43. Amer, W. A.; Wang, L.; Amin, A. M.; Ma, L.; Yu, H. J. Inorg. Organomet. Polym. Mater. 2010, 20, 605-615. doi:10.1007/s10904-010-9373-6

44. Gu, H.; Rapakousiou, A.; Castel, P.; Guidolin, N.; Pinaud, N.; Ruiz, J.; Astruc, D. Organometallics 2014, 33, 4323-4335. doi:10.1021/om5006897

45. Gu, H.; Ciganda, R.; Hernandez, R.; Castel, P.; Zhao, P.; Ruiz, J.; Astruc, D. Macromolecules 2015, 48, 6071-6076. doi:10.1021/acs.macromol.5b01603

46. Rapakousiou, A.; Deraedt, C.; Gu, G.; Salmon, L.; Belin, C.; Ruiz, J.; Astruc, D. J. Am. Chem. Soc. 2014, 136, 13995-13998. doi:10.1021/ja5079267

47. Rapakousiou, A.; Deraedt, C.; Irigoyen, J.; Wang, Y.; Pinaud, N.; Salmon, L.; Ruiz, J.; Moya, S.; Astruc, D. Inorg. Chem. 2015, 54, 2284-2299. doi:10.1021/ic5028916

48. Deraedt, C.; Rapakousiou, A.; Gu, H.; Salmon, L.; Ruiz, J.; Astruc, D. J. Inorg. Organomet. Polym. Mater. 2015, 25, 437-446. doi:10.1007/s10904-014-0161-6

49. Ren, L.; Zhang, J.; Bai, X.; Hardy, C. G.; Shimizu, K. D.; Tang, C. Chem. Sci. 2012, 3, 580-583. doi:10.1039/C1SC00783A

50. Ren, L.; Zhang, J.; Hardy, C. G.; Ma, S.; Tang, C. Macromol. Rapid Commun. 2012, 33, 510-516. doi:10.1002/marc.201100732 
51. Yan, Y.; Zhang, J.; Wilbon, P.; Qiao, Y.; Tang, C. Macromol. Rapid Commun. 2014, 35, 1840-1845. doi:10.1002/marc.201400365

52. Zhang, J.; Pellechia, P. J.; Hayat, J.; Hardy, C. G.; Tang, C. Macromolecules 2013, 46, 1618-1624. doi:10.1021/ma4000013

53. Zha, Y.; Maddikeri, R. R.; Gido, S. P.; Tew, G. N. J. Inorg. Organomet. Polym. Mater. 2013, 23, 89-94. doi:10.1007/s10904-012-9744-2

54. Wang, Y.; Rapakousiou, A.; Astruc, D. Macromolecules 2014, 47, 3767-3774. doi:10.1021/ma5007864

55. Hadjichristidis, N.; Pitsikalis, M.; latrou, H. Adv. Polym. Sci. 2005, 189, 1-124. doi:10.1007/12_005

56. Sankaran, N. B.; Rys, A. Z.; Nassif, R.; Nayak, M. K.; Metera, K.; Chen, B.; Bazzi, H. S.; Sleiman, H. F. Macromolecules 2010, 43, 5530-5537. doi:10.1021/ma100234j

57. Zha, Y.; Disabb-Miller, M. L.; Johnson, Z. D.; Hickner, M. A.; Tew, G. N. J. Am. Chem. Soc. 2012, 134, 4493-4496. doi:10.1021/ja211365r

58. Xu, F.; Kim, H. U.; Kim, J.-H.; Jung, B. J.; Grimsdale, A. C.; Hwang, D.-H. Prog. Polym. Sci. 2015, 47, 92-121. doi:10.1016/j.progpolymsci.2015.01.005

59. Carlise, J. R.; Wang, X. Y.; Weck, M. Macromolecules 2005, 38, 9000-9008. doi:10.1021/ma0512298

60. Metera, K. L.; Hänni, K. D.; Zhou, G.; Nayak, M. K.; Bazzi, H. S.; Juncker, D.; Sleiman, H. F. ACS Macro Lett. 2012, 1, 954-959. doi:10.1021/mz3001644

61. Pawar, G. M.; Weckesser, J.; Blechert, S.; Buchmeiser, M. R. Beilstein J. Org. Chem. 2010, 6, No. 28. doi:10.3762/bjoc.6.28

62. Yan, Y.; Deaton, T. M.; Zhang, J.; He, H.; Hayat, J.; Pageni, P.; Matyjaszewski, K.; Tang, C. Macromolecules 2015, 48, 1644-1650. doi:10.1021/acs.macromol.5b00471

63. Bergens, S. H.; Sullivan, A. D.; Hass, M. Heterogenous rhodium metal catalysts. U.S. Patent 8,962,516 B2, Feb 24, 2015.

64. Il'icheva, A. I.; Barinova, Yu. P.; Bochkarev, L. N.; Il'ichev, V. A. Russ. J. Appl. Chem. 2012, 85, 1711-1717. doi:10.1134/S1070427212110146

65. Barinova, Yu. P.; llicheva, A. I.; Bochkarev, L. N.; llichev, V. A.; Kurskii, Yu. A. Russ. J. Gen. Chem. 2013, 83, 72-79. doi:10.1134/S107036321301012X

66. Miao, W.-K.; Yan, Y.-K.; Wang, X.-L.; Xiao, Y.; Ren, L.-J.; Zheng, P.; Wang, C.-H.; Ren, L.-X.; Wang, W. ACS Macro Lett. 2014, 3, 211-215. doi: $10.1021 / \mathrm{mz} 5000202$

67. Rozhkov, A. V.; Bochkarev, L. N.; Basova, G. V.; Abakumov, G. A. Russ. J. Appl. Chem. 2012, 85, 1930-1938. doi:10.1134/S1070427212120233

68. Nguyen, M. T.; Holliday, B. J. Chem. Commun. 2015, 51, 8610-8613. doi:10.1039/c5cc01719j

69. Feng, W.; Zhang, Y.; Zhang, Z.; Su, P.; Lü, X.; Song, J.; Fan, D.; Wong, W.-K.; Jones, R. A.; Su, C. J. Mater. Chem. C 2014, 2, 1489-1499. doi:10.1039/c3tc31814a

70. Zhang, Z.; Feng, H.; Liu, L.; Yu, C.; Lü, X.; Zhu, X.; Wong, W.-K.; Jones, R. A.; Pan, M.; Su, C. Dalton Trans. 2015, 44, 6229-6241. doi:10.1039/C5DT00141B

\section{License and Terms}

This is an Open Access article under the terms of the Creative Commons Attribution License

(http://creativecommons.org/licenses/by/2.0), which permits unrestricted use, distribution, and reproduction in any medium, provided the original work is properly cited.

The license is subject to the Beilstein Journal of Organic Chemistry terms and conditions:

(http://www.beilstein-journals.org/bjoc)

The definitive version of this article is the electronic one which can be found at:

doi:10.3762/bjoc. 11.296 